\title{
COMMUNITY PARTICIPATION APPROACH IN MANAGING CONFLICTS AS THE IMPACT OF TOURISM DEVELOPMENT
}

\author{
Rd. Ahmad Buchari \\ Padjadjaran University \\ Bandung, Indonesia \\ ahmad_buchari@yahoo.com
}

\author{
Arip Rahman Sudrajat \\ Padjadjaran University \\ Bandung, Indonesia
}

\begin{abstract}
Various changes that take place as an impact of tourism development may turn out to be a source of conflicts among those who feel that they have some economic interests in the tourism development. Tourism is one of the economic sectors that are potential to be made as a source of revenues for individuals, communities, and even local government. Therefore, the management of the effects of disagreements and conflicts resulting from the tourism development of a locality is highly needed. A conflict management may be accomplished by an inclusively participatory planning. An inclusively participatory planning is one that involves the whole people with any interest in an activity plan (Lubis: 2001). It includes modeling, participatory, and scenario planning approaches.
\end{abstract}

Keywords- communitu participation, tourism development, managing conflicts

\section{INTRODUCTION}

When reformation is proceeding and local economic demands are growing, an informed development planning that includes the entire layers of communities is needed. The advent of democratic atmosphere makes people more courageous in voicing their aspirations on developing their localities. This requires local governments, as the policy makers, to be more cautious and to be more caring on people demands.

Tourism development in localities that may expectantly increase own-source revenue (Pendapatan Asli Daerah-PAD) has a great potential of bringing about basic transformations in people's life sphere. Therefore, involving community participation in each tourism development planning in localities should be conducted in order that the diverse interests that base the development of a tourism resort can be accommodated properly. By a community participation approach, it is hoped that the negative impact resulting from the changes due to tourism development in localities can be minimized.

Given the background above, the present study attempted to deal with a topic of tourism development in a regional autonomy which is one of the economic sectors of high importance for the progress of national development.

\section{REGIONAL AUTONOMY: OPPORTUNITIES AND CHALLENGES}

Would regional autonomy be always of a positive meaning? What can be deemed as negative aspects or potentially lead to something negative? An understanding on any negative aspects of autonomy is needed in order that we can anticipate anything that is likely to happen. According to Abe (2001), the negative aspects that may develop from the existence of regional autonomy are as follows:

First, chances of conflicts between localities, resulting from resource conflicts. A superficial understanding on regional autonomy has built an image that local autonomy is the same as automoney. This opinion makes regional autonomy reduced to simply a matter of PAD. Therefore, each locality busily consolidates itself to develop or earn a large PAD. It may be done by: 1) developing a tax scheme; 2) attracting foreign investors; and 3) exploiting maximally natural resources. In the case of the latter, the regional autonomy process simply triggers an environment-destructing process, or as a process that betrays environment and natural conservation.

Second, discrepancy between localities. A regional autonomy actually assumes an occurrence of normal politic process, as indicated by "capacity of central government". A strong leadership is needed to successfully develop coordination between localities. Why is it that? It is really inseparable from the reality that different localities actually have different potentials. This condition certainly may lead to an unbalanced interregional development. Rich localities will, of course, utilize their autonomy as a momentum of revival for their locality. In contrary, for those localities with poor resources, autonomy may means as a disaster, particularly if coordination isn't maximal and the distribution of national wealth is not going on properly. It can be reasonably predicted that discrepancy between localities will emerge. And, if it is the case, such condition is likely to spark off disintegration and results in interregional conflicts.

Thirdly, appearance of local injustice and emergence of little kings in localities. The autonomy processes that mean as a delegation of authority to the government and elite of regions will certainly be of little value if it isn't followed by political processes that open an opportunity for people participation. This is precisely the problem, that is, the 
opening of chances for manipulation by regional elites, who basically want to restrict or even prevent participatory political processes in favor of elitist political processes. Furthermore, given the emergence of aspirations or demands on the development of adat (local customs) as a foundation of autonomy implementation, it is very likely for a feudalistic relations model to emerge. If so, autonomy is no more than just an authoritarianism transfer process rather than a transformational medium.

The implementation of regional autonomy, in just around three years since its introduction, has indicated that there are some things undesirable and deviations in the regional autonomy practices. Of course, this ramification is undesirable because it generates a bad image to regional autonomy. Nevertheless, the symptom can be understood given that the regional autonomy has been implemented under two conditions that are less conducive for the growth of regional autonomy (Raul: 2002). Firstly, regional autonomy was brought about amid a very severe economic crisis. Autonomous localities need huge financial sources because they have to finance their own various necessities, whereas the state has very low economic growth, investments were extremely hard to get, and those sources that can earn moneys were so limited. Therefore, it isn't surprising that lots of regencies (districts) and municipalities pursued diverse ways of enhancing their own-source revenues.

Secondly, regional autonomy was implemented amid a public euphoria, that is, high spirit and confidence that communities can accomplish whatever they want. Thus, it isn't surprising that there appeared various demands and protests from different layers of people that were often violent in nature and beyond reasonable limits, e.g., by burning local police parliament, and government' offices. Such psychological atmosphere was also affected by a strong sense of freedom so that regional autonomy was implemented amid of chaos and legal uncertainty.

\section{TOURISM DEVELOPMENT IN REGIONAL AUTONOMY}

Tourism is one of the crucial economic sectors in driving national development rate. The same applies to regional governments. In a framework of regional autonomy, each regional government with excellent tourism potentials races to seek advantages by exploiting the sector. It is undeniable that tourism development would be of significant impacts, both positive and negative. In the course of its development, tourism induces some conflicts in land utilization and alters the socio-economic characteristics of the tourism destinations.

Mantra (1992), observing the impacts of tourism in Bali and Yogyakarta, suggested the occurrence of dynamics in local communities/around tourism resorts including changes in lifestyle, solidarity and community bonds, women' roles, and perceptions on religion, beliefs, and cultural values. In a deeper analysis, Mantra (1993) also found out some change in populations' structures due to development of tourism industry in Bali province. Besides from influencing socio-cultural environments, tourism development in the localities with rural background also impacts physical environment, as reflected by the changes in land utilization from agriculture to no- agriculture (Susetyaningsih: 2001). The conversion of open lands into built lands in the interest of tourism has also some impact in form of decreases in the quality of physical environment such as increasing micro-temperature, decreasing groundwater absorption potentials, and so on.

Considering that tourism is a complex phenomenon that may induce differences and conflicts, it is desirable that both planners and policy makers, in this case local governments, have competence in managing both positive and negative impacts that a tourism development may result in. Though the tourism development may contribute to fulfilling own-source revenues, the sustainability of the tourism activities themselves should be taken into account. The sustainability may be achieved if there is a harmonious relationship between those who have interests in tourism, in this case local governments, investors, and local communities.

The emerging democracy climate as a result of reformation is hoped to be a control of the negative impact of tourism. However, democratic freedom should also be watched in order that it is not abused and used as a means of those individuals/groups who are dissatisfied or who perceive that they are disadvantaged by a tourism activity.

The reformation proceeding in Indonesia since 1997 has open long-suppressed democratic channels. It is grounded in a rationale that both freedom and equality to be realized in a society require the existence of freedoms of thought, of expression, of voice, of assembly, and of organizing. It leads all individuals and groups perceive as having a right of voicing their personal/group interests against possible violations by other individuals/groups, including the state.

Regional autonomy is one of the real forms of democratic practices. In a framework of regional autonomy, the freedoms expected for individuals and localities are a requirement of advancement. Individual advancement may hopefully affect the development of not only the individuals themselves but also that of the society as a whole. In a regional autonomy setting, the advancement of a locality would expectantly contribute to the advancement of the entire nation. Thus, the rationale is that the advancement should begin with the development of individual self-sufficiency (in democracy) and localities (in regional autonomy).

Though freedom is deemed as one of the essential factors in the advancement of communities, it has a great potential of destructing them as well. If the freedom induces conflicts and it is not offset by competence in solving them then violent conflicts will take place among communities. Eventually, such violent conflicts would have some impact by weakening the state and even creating a social disintegration.

\section{FRAMEWORK OF ANALYSIS}

In a framework of regional autonomy, there are three stakeholders of the development of tourism sector, namely, the local government, investors, and local people. The local government has an interest in the development of tourism because the sector will expectantly contribute to increasing own-source revenues, particularly from taxes and retributions. Autonomous localities need the great financial sources to 
finance their own expenditures. Some of the financial sources of the tourism economic sector are hotel, restaurant, and other entertainment taxes and retribution from tourism object entry tickets.

The second party with some interest in the development of tourism is investors who invest in the sector. As investors, they are certainly adept in assessing the extent of potential that a tourism object or area possesses. A great potential of tourism development is likely to affect the advancement of businesses and hence the economic profits of the invested capitals.

The third party with some great interest in a tourism development is local population/society who is living around the tourism resort. The existence of tourism activities in their locality may of course be made as a source of additional revenues and thus may enhance their prosperity, either directly or indirectly.

In fact, a tourism development in an area doesn't always fulfill the expectation of the stakeholders above. The discrepancy between expectation and reality may, if left unsolved, induce a stress. The emergence of diverse impacts in forms of alterations in both physical and socio-cultural and economic environments, either positive or negative in nature, should be properly dealt with. Without such management, the discrepancy in interests and/or occurrence of stresses may stimulate a conflict.

The impacts of tourism development on socio-cultural and economic environments include: changes of livelihood, lifestyle, solidarity and community bonds, women roles, and perception on religion, faith, and cultural values. Moreover, the great potential of conflicts due to the changes in livelihood, lifestyle, and solidarity dynamics and community bonds would occur if there were discrepancy among those societal groups who are living around the areas of tourism development.

\section{THE MANAGEMENT OF CONFLICTS AS THE IMPACT OF TOURISM DEVELOPMENT}

A way of managing conflict potential as an impact of tourism development is by a participatory planning inclusively. According to Lubis (2001), there are three alternatives of basic approach in planning the development of an area. First alternative is by a financing approach. In solving a conflict, courage is needed for delineating a problem with a solution by an existing model and it should be pursued in attempt to accomplish the goal. In this model approach, a group of experts works together exploring the alternative future of the region and through an empirical relationship between previous data. Performance as a policy alternative is examined relative to the accomplishment of the goal of planning, in order to obtain the best policy.

Basically, we should be brave to propose and create an appropriate model of conflict management. Each problem can be solved if the model we apply can provide input and in the same time comes out as an alternative of problem solving. The model should be suitable for short- and long-term changes.
Second alternative is a participatory approach. Nowadays, it is very appropriate to use this approach, given that people are increasingly aware that the involvement of all actors or stakeholders in a policy-formulating process which is most essential in winning public commitment to make a change. By involving all stakeholders, in a forum, it would make possible for an occurrence of a creative discussion, opinion exchange, information sharing, and finding of a conflict resolution.

Third alternative is a scenario planning or scenario analysis approach, intended to, among others: 1) gather information from all stakeholders relating to the development plan, 2) attempt to learn value systems, perceptions, hopes, and options of resolution that come out in the mind of the stakeholders, 3) try to develop relationship and communication with fellow stakeholders, 4) develop a leaning forum, particularly by trying to understand other stakeholders' perspectives, and 5) develop and facilitate creative thoughts in seeking and developing resolutions. The attraction of using the scenario in this case is that it can explain a future picture in certain special frameworks and assumptions.

\section{Closure}

To apply a participatory approach, it needs some requirements, among others: each actor should have a sufficient motivation to participate, and they should be convinced that the discussed problem and the cooperation of participants are of high importance in searching for ways of resolution so that conflicts can be minimized. In addition, the participants should be convinced that the forum is a pure participation rather than just a platitude, symbolic, or just for public image manipulation.

By combining and taking the advantages of each of the preceding methods, it is hoped that the development of tourism in a locality wouldn't induce significant conflicts. In implementing regional autonomy with all attending socialpolitic dynamics, a reliable planning is needed. Most important is how to blend a good policy with various special local characteristics, involving cultures and natural and human resources. Last-but-not-the-least considerations are the existence of political certainty, as well as current economic and financial conditions.

\section{References}

[1] Abe, Alexander, 2001. Regional Planning: Strengthening People Initiatives in Regional Autonomy, Lapera Pustaka Utama, Yogyakarta.

[2] Fandeli, Chafid, 1995. Fundamentals of Natural Tourism Management, Liberty, Yogyakarta.

[3] Joeniarto, R, 1992. Development of Regional Government, Bumi Aksara, Jakarta.

[4] Lubis, Harun al-Rasyid, 2001. Regional Autonomy and Public Participation. Republika Daily, 1st Edition, Agustus 2001

[5] Mantra, Ida Bagoes, 1992. Structural and Cultural Impacts of Tourism Industry in Yogyakarta and Bali Provinces, A Research Report, PAU UGM, Yogyakarta.

[6] __ 1993. Changes in Population Structure Due to Tourism Industry Development in Bali, Bulletin of Population Policies Research, UGM, Yogyakarta. 
[7] Osborne, David and Peter Palstrik, 1997. Banishing Bureaucracy - The Five Strategies for Reinventing Government. First Published in the United States by Persues Books Publishing A Subsidiary of Persesus Books I.L.C.

[8] Rauf, Maswadi, 2002. Regional Government and Horizontal Conflict, Politic Science Journal, Jakarta.

[9] Splillane, James J, S.J., 1994. Indonesian Tourism: Economic Tricks and Cultural Reengineering , Kanisius, Yogyakarta.
[10] Soekartawi, 1990. Fundamental Principle of Development Planning, with a Special Subject Matter of Regional Development Planning, Rajawali, Jakarta.

[11] Susetyaningsih, Adi, 2001. Development of the Socio-Economic Environment of the People of Cipanas Area, Garut Regency, West Java. A Thesis, UGM Postgraduate UGM, Yogyakarta.

[12] Thoha, Miftah, 2002. Prime Dimensions of Public Administration Science, PT. Raja Grafindo Persada, Jakarta.

[13] Law No. 22 of 1999 on Regional Government.

[14] Law No. 25 of 1999 on Balance of Central and Regional Finance. 